\title{
Estudio de un caso sobre el uso de las tecnologías de la información y la comunicación para la inclusión Social.
}

\author{
Iolanda García, Silvia Lombarte \\ Universidad de Barcelona
}

\section{El papel de las TIC en la vida de los niños y niñas de la era digital}

Las tecnologías de la información y la comunicación (TIC) tienen actualmente un rol clave en nuestra sociedad, pues su desarrollo está provocando rápidas transformaciones en todos los ámbitos. La utilización de las TIC por parte de niños, niñas y jóvenes es considerable y además, se encuentra en plena expansión. Según Suoronta (2003), las TIC se están convirtiendo cada vez más en una parte importante de la vida cotidiana de estos, lo cual tiene implicaciones en la forma en que utilizan su tiempo, e interactúan con las personas de su entorno.

Por lo general, los jóvenes están mucho más familiarizados que los adultos con la cultura digital (Tapscott, 1998), lo que ha dado lugar a un modo de socialización bidireccional: los adultos enseñan, pero también aprenden de sus hijos, así como de otros jóvenes. La cultura de los medios es parte fundamental de la vida cotidiana de los chicos y chicas, pues sus actividades se estructuran alrededor del uso de éstos. Así, las historias e imágenes contenidas en los medios se convierten en ejes importantes para la construcción de su identidad (Feixa, 2001). De hecho, los agentes de socialización tradicional (la escuela y la familia), se encuentran influenciados por las TIC y, en cierta medida, han sido sustituidos por ellas (Suoronta, 2003).

Esta situación está generando un amplio debate sobre el impacto de las TIC en la formación de los menores, el cual se mueve, como también ocurrió con la televisión, entre posiciones más o menos extremas que van desde la utopía al fatalismo. Mientras algunos autores como Minoura (2001), se preocupan por el hecho de que los usos comunicativos de las TIC estén reduciendo el contacto humano; otros, como Lorente (2004), defienden que tecnologías como el teléfono móvil o los chat, actúan como instrumentos de socialización para los más jóvenes, reforzando su sentimiento de pertenencia a un grupo. A parte de los mencionados, se atribuyen a Internet otros peligros que afectan directamente a la integridad de la infancia, como la pornografía infantil o la pederastia. Si bien es cierto, la capacidad de un niño o un joven para interpretar y hacer frente a este tipo de problemáticas, depende precisamente de sus competencias personales y del conocimiento que tenga de estos nuevos medios.

Pero no solo el acceso, sino también el hecho de conocer o no las estrategias y herramientas implicadas en el uso de las TIC, puede dar lugar a diferencias entre niños/as y jóvenes. Como describimos a continuación, en el estudio de caso realizado, los distintos usos de las TIC por parte de los jóvenes, ya sean formales o informales, pueden constituir tareas de aprendizaje. Actividades como leer un texto y comprenderlo, en formatos y mediante utensilios tan diferentes como un ordenador, un reproductor de cds, un teléfono móvil, o un equipo de vídeo, son requisitos de lo que se ha denominado alfabetización digital (Area, 2001). Por ejemplo, las salas de chat se pueden contemplar como un foro pedagógico que facilita el aprendizaje, como por ejemplo en el dominio del lenguaje, o la comunicación válida. Al enviar mensajes de texto a través del teléfono móvil, los jóvenes producen 
nuevas formas de comunicación y recrean el lenguaje. Algunos estudios muestran como los videojuegos mejoran la capacidad sensorial y la percepción estética, así como contribuyen al desarrollo de gran cantidad de capacidades cognitivas (Rodríguez, 2004). El relativo descenso del precio de los ordenadores, en paralelo al desarrollo del diseño de programas informáticos permite, a gran número de jóvenes, realizar sus propias creaciones, por ejemplo musicales. Esta nueva forma de cualificación de los jóvenes, con frecuencia adquirida mediante el aprendizaje informal, debe ser considerada como una oportunidad para el desarrollo personal y social (Suoronta, 2004; Brader, 2001). Se debe proveer a los niños y a los jóvenes de oportunidades para adquirir capacidades en múltiples formas de alfabetización, que actúen como soporte en el desarrollo de sus relaciones sociales y comunitarias, ya sean éstas materiales, virtuales, o una combinación de las dos.

Según las investigaciones de Hellawell (2001), la utilización de las TIC puede ayudar a desarrollar nuevas capacidades y mejorar la empleabilidad y la confianza en uno mismo. Aprender a utilizar Internet puede suponer, para los jóvenes, una oportunidad de relación y desarrollo de lazos de amistad. Esta idea está relacionada con los planteamientos de Castel (1992) sobre la vulnerabilidad social, quien define la zona de integración social a partir del hecho de tener un trabajo estable, pero además, una inscripción relacional sólida, tanto familiar como vecinal. En el caso de los adolescentes, los lazos de amistad pueden proporcionar esta red de relaciones, que favorecerá su inclusión social.

Para lograr el acceso a las TIC, se requiere una alfabetización digital, definida como "conjunto de hábitos a través de los cuales se interactúa con las tecnologías de la información y la comunicación para aprender, trabajar, socializar, divertirse, etc." (Ba, Tally y Tsikalas, 2002). Pero ni todos los jóvenes tienen acceso a las experiencias de interconexión, ni estas tienen las mismas características, como expresan las conclusiones del estudio realizado por Ba, Tally y Tsikalas (2002). En este estudio se compara el uso del ordenador en el caso de niños y niñas de familias con niveles de ingresos bajo y medio, en distintos barrios de la ciudad de Nueva York. Los autores concluyen que las capacidades para el uso de las tecnologías reflejan las circunstancias locales de cada niño/a. Esta situación remite a la idea de fractura o brecha digital (digital divide) la cual consiste, en su sentido más genérico, en la distancia entre aquellas personas y comunidades que dominan, acceden y utilizan eficazmente las TIC, y aquellas que no (BECTA, 2001)[1]. La disparidad en las posibilidades de acceso en la cultura de los medios refleja las ya reconocidas diferencias en ingresos, salud y educación. De hecho, las desigualdades en la difusión de las TIC son consecuencia de las profundas discrepancias económicas, sociales, políticas y educativas de las sociedades del mundo actual.

En distintos países se están impulsando iniciativas de utilización de las TIC para la inclusión social, que están dando buenos resultados[2]. Una de las más reconocidas y extendidas en España es el Proyecto ÓMNIA, desarrollado en Cataluña (www.xarxa-omnia.org). Este proyecto se basa en ofrecer acceso a ordenadores, Internet y otros medios, a toda la población, en los llamados puntos Ómnia. Los puntos se encuentran integrados en entidades sin afán de lucro y se localizan en los barrios más desfavorecidos de las principales ciudades de Cataluña. Los ejes principales del proyecto son: el uso comunitario, la inserción sociolaboral y la formación.

\section{Marco Metodológico}

Antes de entrar a describir con más detalle los métodos utilizados en nuestro trabajo, queremos aclarar que el estudio de caso que presentamos a continuación es solamente una aproximación exploratoria a esta temática. No pretendemos ofrecer datos significativos ni generalizables sobre el estado de la cuestión, sino por el contrario, nos proponemos describir una experiencia concreta, para recoger la "buena práctica" que supone, y contribuir a su adaptación en realidades similares. A continuación resumimos los objetivos del trabajo realizado:

a) Describir la Associació per a Joves TEB, como ejemplo del uso de las TIC para la inclusión social.

b) Analizar los componentes de este tipo de experiencias, sus puntos fuertes y débiles para comprender el papel de las TIC en los procesos educativos.

c) Dar a conocer la experiencia como una buena práctica, que se puede adaptar a distintas situaciones 
y circunstancias, como un recurso para la superación, o prevención de situaciones la exclusión social.

Somos conscientes de las limitaciones de este estudio exploratorio. No obstante, pensamos que es interesante como primera aproximación a la realidad descrita. En la recogida de datos del estudio de caso, hemos utilizado las siguientes fuentes y procedimientos:

Referentes teóricos; para la elaboración del marco teórico recogido en el primer apartado. Hemos utilizado, tanto bibliografía de tipo teórico, como investigaciones de autores de escala internacional y local (catalanes), con la finalidad de conseguir una visión global sobre el tema y, a su vez, un conocimiento más local de la realidad que posteriormente se analizará en el estudio de caso.

Observaciones: con la finalidad de impregnarnos de la realidad que nos interesaba analizar y poder describirla, elaboramos un protocolo de observación. Construimos categorías que nos pudieran aportar conexiones entre el uso de las TIC y la inclusión social de los jóvenes, pero a la vez, dejamos una parte más abierta para poder recoger otros aspectos relacionados con el tema, que nos llamaran la atención. Las observaciones no solamente nos sirvieron para describir las categorías más interesantes, sino también para concretar algunas de las entrevistas con los jóvenes participantes y los educadores.

Entrevistas con los jóvenes participantes: para las entrevistas con los jóvenes se elaboró un cuestionario semi-estructurado que se fue reelaborando a medida que se iba obteniendo información, tanto mediante las observaciones, como con las primeras entrevistas. Pensamos que esta fuente de información tiene gran importancia, ya que los informantes son las personas que viven el proceso cotidiano de adaptación social y pueden valorar el papel que juegan dentro de éste, el acceso y el uso de las TIC.

Entrevistas con los dinamizadores: consideramos que era importante contrastar la visión de los jóvenes con la de las personas adultas que están supervisando las actividades dentro del centro ya que, en definitiva, son quienes pueden valorar si realmente los objetivos que plantea el proyecto se están cumpliendo.

\section{Estudio de caso: La Associació de Joves TEB}

La Associació per a Joves TEB nació con el objetivo de luchar contra la exclusión social de los jóvenes del Raval, un barrio "marginal" de la ciudad de Barcelona, con una elevada proporción de personas de origen inmigrado, que provienen de países en vías de desarrollo. La metodología del TEB parte de la capacidad de autoorganización de los jóvenes del barrio, potenciando así el valor de la responsabilidad, y ofreciendo alternativas distintas a las de la calle, con la intención de conseguir una inserción social real. Para conseguir este objetivo el TEB, realiza un trabajo de desarrollo de las competencias sociales, es decir, potencia aquellas habilidades que les permitan desenvolverse mejor en el mundo en el que viven. El funcionamiento es cooperativo y asambleario, de forma que los jóvenes más mayores de la asociación se impliquen en el compromiso hacia los otros jóvenes del barrio y hacia el Raval, en general.

El TEB se encuentra dentro de la red ciudadana del Raval, la cual actúa a través del portal Ravalnet (www.ravalnet.org). En la actualidad, esta asociación tiene diversos proyectos relacionados con el uso de TIC. El perfil de los educadores es diverso, aunque en general tienen formación sobre TIC. Algunos de ellos son vecinos del barrio y muchos, antiguos colaboradores. En cuanto a los/as participantes, la mayoría son procedentes de otros territorios, como por ejemplo del Magreb, Pakistan, India, o América del Sur. Algunos son recién llegados, otros son segundas generaciones de inmigrantes, aunque también podemos encontrar a jóvenes de origen catalán que han vivido siempre en el barrio. La mayoría de los jóvenes conocen por primera vez el centro por el "boca a boca", o bien se les deriva desde el centro educativo (instituto o escuela). Algunos llegan a través de los educadores de calle del barrio y unos pocos son derivados desde servicios sociales. Una cierta proporción participa desde que se inició el proyecto, aunque a la vez, las incorporaciones y las salidas son también constantes. 
Los talleres que se realizan en este momento son: programas de radio, un servicio laboral, Casalnet (creación de cortometrajes), Raval en Brasil (intercambio de experiencias con Brasil), Ravalsurf (utiliza el surf como una actividad lúdica, que permite a la vez desarrollar capacidades y facultades), Creaciones CD-ROM y multimedia.

Nuestra investigación se desarrolló en el espacio libre. Este tipo de actividad transcurre en una sala habilitada con ordenadores conectados a Internet. En este espacio pudimos observar que, pese a existir unas normas mínimas de utilización de los ordenadores (como el tipo de páginas que se pueden ver, o el tiempo que pueden ocupar el ordenador), se les da bastante libertad para que cada uno haga lo que prefiera con o sin ellos. Tienen destinadas diferentes franjas horarias y cada uno se apunta cuando le va bien, coincidiendo, en algunos horarios, jóvenes y adultos utilizando los ordenadores. Los dinamizadores son las personas que controlan el espacio y ofrecen ayuda o explicaciones referentes al uso de los ordenadores o programas, deberes de la escuela, etc. a quienes lo requieren.

\section{Análisis}

\subsection{ACTIVIDADES QUE SE REALIZAN}

En el espacio libre, los jóvenes hacen uso de los ordenadores para gran variedad de actividades, como exponemos a continuación:

Los juegos de ordenador tratan sobre fútbol y tenis, carreras de motos o coches, o son de tipo más educativo. Otros posibles juegos aprovechados son los que se encuentran en Internet. En cuanto a programas informáticos más específicos, los jóvenes utilizan sobre todo los de diseño o tratamiento de imágenes. Por ejemplo utilizan el Flash para hacer montajes con imágenes en movimiento, programas de creación de páginas web con los que diseñan la suya, como el Dream Weaver, o el programa de dibujo Corel Draw. En ocasiones estos programas se trabajan a partir de un taller y los chicos y chicas continúan utilizándolos en el espacio libre.

Otro de los usos más atractivos para los jóvenes es el de las herramientas de comunicación a través de Internet. El programa más utilizado en este sentido es el Messenger y, algo menos, el correo electrónico. Internet se usa además como soporte para realizar búsquedas de información sobre temas tan diversos como música, series o telenovelas de televisión, deportes, o cuestiones escolares, etc. Al igual que Internet, los ordenadores se utilizan como soporte para realizar trabajos de la escuela. Algunos chicos disponen de una carpeta donde van almacenando aquello que desean, productos elaborados personalmente, imágenes, etc. Existe también una oferta de actividades organizadas por desde la Red Ómnia (www.xarxa-omnia.org), que los chicos y chicas pueden escoger de forma voluntaria.

\subsection{SENTIDO Y MOTIVACIÓN DEL ESPACIO DE USO LIBRE}

No se puede negar que el TEB ejerce una fuerte atracción sobre los chicos y chicas del barrio. Existen diferentes razones para explicar esta motivación que, en algunos casos, se remonta a los inicios de la entidad y ha continuado hasta hoy. Según dos educadores del equipo responsable del TEB, los jóvenes acuden en busca de entretenimiento y diversión, aunque, sin saberlo, aprenden informática y amplían sus posibilidades de acceso a información de todo tipo a través de Internet.

Para la mayoría de ellos, el encanto principal del TEB es la posibilidad de utilizar el ordenador, con todas las alternativas que este ofrece, entre ellas la conexión a Internet. Esta motivación no es, como sabemos, exclusiva para los jóvenes del Raval. El uso del teléfono móvil y de Internet, por ejemplo, o del programa Messenger, atraviesa a chicos y chicas de diferente estatus socioeconómico, cultura y edad, como hemos señalado en el apartado teórico inicial. Pero, al margen del carácter lúdico, casi todos los chavales con los que hemos hablado, valoran al TEB por lo que aprenden, por la posibilidad de encontrar asesoramiento y recursos para hacer los deberes de la escuela, etc. 
Con una andadura de 13 años en el barrio, éste centro se ha convertido en todo un referente y un espacio de encuentro para los jóvenes del entorno. Algunos de ellos insisten en que las TIC no son la razón principal por la que van al TEB, si no la posibilidad de conocer a gente, hacer amigos y relacionarse con ellos. En efecto, y como hemos explicado anteriormente, el centro cuenta con espacios y recursos alternativos a la sala de ordenadores, como una sala con televisión y video, salas de reunión, un estudio de grabación, un futbolín, etc. Así, hemos podido observar como, mientras algunos utilizan el ordenador, otros juegan, conversan, corren, etc. por los diferentes espacios del centro.

En general, lo que se intuye, tanto por los comentarios de los chicos y chicas, como por la atmósfera que se respira, es que se trata de un espacio libre y abierto a la diversa realidad del barrio. En el TEB no existe una presión manifiesta por cumplir unos objetivos de aprendizaje, ni la obligación de realizar unas tareas determinadas como ocurre en la escuela. La relación de confianza entre dinamizadores y "usuarios" es vivida seguramente de forma muy distinta a la experimentada con el profesorado. Los participantes acuden al TEB al salir de clase. Allí se sienten respetados y cómodos, a la vez que encuentran un espacio de convivencia y aprendizaje mutuo entre diferentes culturas. Por ejemplo, los dinamizadores utilizan la lengua que resulta más eficaz para la comprensión en cada caso y los chicos y chicas pueden expresarse en aquella que se sienten más cómodos.

"Es libre, es ... , conoces gente, tienes otras culturas a tu lado. En vez de estar en la calle perdiendo el tiempo...". (Adolescente participante en el TEB)

Para acabar, debemos referirnos a una cuestión nada marginal, como es la pequeña proporción de chicas que encontramos en el TEB. De entrada, podemos atribuir esta asistencia significativamente menor a un problema de motivación, otra cuestión es a qué se debe esta falta de interés y a eso nos referimos más adelante.

\subsection{RED SOCIAL}

El TEB es un espacio abierto, dinámico y por lo tanto conocido en el barrio. Por la propia naturaleza del proyecto, este se plantea realizar una función de ventana al exterior, a través de la cual dar a conocer el barrio y su gente. Por este motivo, muchas de las actividades que se realizan en el centro, ya sea con adultos o con jóvenes, tienen, por un lado, una proyección externa (ya sea en forma de exposición, pase de video, página web, encuentro, etc.) y, por otro, la intención de involucrar al vecindario en éstas. Con esto, se contribuye a crear redes internas dentro del propio barrio, a la vez que se moviliza a sus habitantes para una participación activa en la vida comunitaria.

El propio local del TEB es un lugar en que se dan cita personas de generaciones e intereses diversos. Como ya hemos explicado, existen cursos y talleres dirigidos a adultos o a jóvenes, pero también existen situaciones en que personas de diferentes edades comparten el mismo espacio e intereses comunes. Pensamos que estas situaciones son muy positivas, pues proporcionan oportunidades para establecer puentes intergeneracionales, por otra parte, bastantes escasas en la sociedad actual. En cierta forma, los roles de autoridad y obediencia, de conocimiento e ignorancia, que corresponden, en contextos cotidianos, a adultos y a jóvenes o niños respectivamente, quedan desdibujados, e incluso pueden llegar a invertirse en estas ocasiones.

Algunos de los chicos que comparten su interés por las TIC van también a locutorios o cibercafés del barrio, por lo que queremos destacar el papel socializador de estos centros, aunque su cometido no sea intencionadamente educativo. La escuela proporciona unos conocimientos mínimos sobre el uso de las TIC, los cuales pueden afianzarse en lugares como locutorios, cibercafés o el TEB. De esta forma, el TEB contribuye al desarrollo de una red social y de recursos de los participantes, necesaria para estar integrado socialmente. 
El dinamizador o dinamizadora es la persona que acompaña a los jóvenes en el TEB. En función de la situación, esta persona orientará, ayudará, animará, enseñará o controlará las actividades de los chicos y chicas. Nos referimos esencialmente al papel del dinamizador en el espacio de uso libre de las TIC, entendiendo que en los talleres, el rol ha de ser algo más directivo y proactivo, puesto que se está ofreciendo una formación específica y programada con antelación. En el espacio libre, el papel del dinamizador/a está muy supeditado a las características y necesidades de los participantes en distintos momentos. La mayor parte de chicos son muy independientes y solo reclaman ayuda cuando no encuentran la solución por sí mismos. No obstante, algunos requieren más atención, por ejemplo si son nuevos, o tienen menos conocimientos en relación a las TIC. Colaboran también con los jóvenes en la realización de sus deberes de la escuela, si es que éstos lo solicitan.

Pero el papel de los dinamizadores consiste además en hacer que los niños y jóvenes amplíen sus miras y, a parte de los juegos y del Messenger, se interesen por el funcionamiento de otro tipo de software o actividades, como por ejemplo programas de diseño. En el espacio libre no existe una propuesta explícita de actividades, si no que se espera a que sean ellos los que propongan o decidan lo que quieren hacer. Con esto se pretende desarrollar su iniciativa, hacer que se impliquen verdaderamente en lo que hacen, en definitiva, en el proceso educativo. Los dinamizadores se encargan de recoger las propuestas de los participantes, ya sean estas directas o indirectas y más o menos explícitas, para luego orientar las actividades en ese sentido. A la vez, estimulan la aparición de motivaciones desconocidas por niños y jóvenes, que promuevan nuevos aprendizajes por su parte.

Cuando llega un chico o chica nuevo, se le explica lo necesario para que pueda hacer lo que quiera, siempre partiendo de su nivel de conocimientos. Generalmente se empieza por implicarlo en actividades lúdicas en que puedan participar otros chavales, como en el caso del futbolín, por ejemplo. A partir de aquí se logra el primer acercamiento entre esta persona y el resto. En algunos casos, el hecho de desconocer las mutuas lenguas supone un gran handicap, ya que cuesta llegar a comprenderse. En estos casos, los educadores/as tienen un importante papel como mediadores.

\subsection{TRABAJO EDUCATIVO}

Los beneficios de las actividades realizadas en el TEB, en términos educativos, para los participantes son variados. Podemos hablar de beneficios en cuanto a aprendizajes, desarrollo de capacidades y habilidades, así como de adecuación del comportamiento a cada situación.

Los conocimientos se refieren fundamentalmente al uso de las herramientas tecnológicas, así como del funcionamiento de cada programa concreto.

Las capacidades y las habilidades constituyen aspectos más genéricos del aprendizaje y, por lo tanto, más fácilmente transferibles a otros contextos, como pueda ser el laboral, el personal, el social, etc. Los educadores entrevistados se refirieron a las siguientes.

a) Capacidad para organizar un proceso y saber seguir el conjunto de acciones que lo componen ordenadamente, respetando los tiempos y los procedimientos. Con el programa Flash, los chicos aprenden que si no lo hacen de esta forma, no podrán conseguir lo que se han propuesto.

b) Capacidad de trabajo durante un cierto período de tiempo para conseguir unos objetivos a largo plazo. Con el trabajo en los talleres, pero también en el uso de programas informáticos en general, los chicos se dan cuenta de que existen objetivos que no se pueden conseguir de forma inmediata, si no que antes es necesario aprender y, a veces intentarlo varias veces, antes de lograrlo.

c) Habilidades para comunicarse a través de herramientas tecnológicas, ya sea el correo electrónico o el Messenger. Paralelamente al aprendizaje de su funcionamiento, se trabajan algunas competencias básicas como la lectura y la escritura. Los chicos deben esforzarse con el lenguaje para ser comprendidos por sus interlocutores y los dinamizadores no dejan pasar esta oportunidad para instarlos a escribir correctamente.

d) Habilidades para resolver problemas. Cuando uno de los ordenadores de la sala se estropea, la 
reparación se realiza en uno de los talleres del TEB, no obstante, cuando el ordenador "se cuelga" u ocurre un problema menor, se aprovecha para proporcionar recursos a los jóvenes sobre lo que hacer en estos casos.

Por último, existe un tipo de aprendizajes que tienen que ver con las actitudes o valores de los jóvenes. En este sentido, se atiende de forma especial al desarrollo del respeto mutuo, de la autoestima y de la dignidad de los chicos y chicas participantes.

\subsection{FORMAS DE CONTROL}

Por control nos referimos, en este caso, a las medidas adoptadas por los educadores para ajustar los comportamientos de los participantes y el funcionamiento del centro. Estamos hablando esencialmente de normas, con relación al uso de las TIC.

Uno de los miedos adultos hacia la facilidad con que los y las jóvenes utilizan las TIC, tiene que ver sobre todo con el contenido inadecuado de algunas páginas web, o con la posibilidad de que adultos con intenciones poco honestas contacten con estos/as[3]. En el TEB, existe una posición de alerta muy sosegada frente a estos temas. Por ejemplo, aunque una de las normas de uso de los ordenadores prohíbe el acceso a páginas pornográficas o con contenidos violentos (como tampoco pueden utilizar juegos de ordenador violentos), no es una cuestión que les preocupe especialmente, puesto que nunca han tenido problemas relacionados. En algún momento, se ha utilizado el cortafuego de la red local como filtro para algunas páginas web, pero en otros esta protección no ha existido y sin embargo eso no ha supuesto ningún cambio.

Por lo que respecta al uso de las herramientas de comunicación como el Messenger o el chat, tampoco existe una voluntad manifiesta, por parte de los dinamizadores, de controlar con quien se comunican. Estos comentan que en general los chicos y chicas hablan con personas que conocen, ya sea directa o indirectamente.

En general, los aspectos que más preocupan a los educadores son otros, como por ejemplo, el uso adictivo, o durante un tiempo demasiado elevado, de los juegos de ordenador y del propio Messenger. Una de las medidas, ya implantadas en el caso de los juegos, para evitar situaciones de uso descontrolado, es limitar a media hora el tiempo de ocupación de los ordenadores para jugar. Este es el tiempo máximo que pueden emplearlos en toda una tarde, después de solicitarlo apuntándose a una lista, independientemente de que los ordenadores estén o no disponibles. Una medida como esta puede resultar excesiva dentro de un contexto de uso libre de las TIC, pero no se debe olvidar que el TEB es, ante todo, un espacio educativo y relacional, donde lógicamente deben evitarse posibles situaciones de aislamiento de los participantes.

\section{Consideraciones Finales}

Centros como el TEB ofrecen alternativas a jóvenes y adultos que no tienen acceso a las TIC en sus propias casas. Los educadores del TEB consideran que esta falta de acceso puede colocarlos en una posición de desventaja, al igual que diversos autores (Castells, 1997; Area, 2001). Algunas estrategias para acercar las TIC a jóvenes y adultos, que carecen de medios de acceso, consistirían, por ejemplo, en poner a disposición ordenadores conectados a Internet de uso gratuito, en escuelas y bibliotecas. Los educadores comentan que la escuela realiza una función importante al dar a conocer las herramientas básicas para la utilización de estas tecnologías, pero falla al no permitir un acceso abierto a ellas, como por ejemplo se hace en las universidades. Esta apertura tendría dos consecuencias positivas: a) por una parte se facilitaría el aprendizaje efectivo del uso de ordenador e Internet, especialmente para aquellos que no tuvieran acceso en casa; b) por otra parte, el hecho de poder hacer los deberes o trabajos de la escuela en este espacio, podría resultar beneficioso para la motivación del alumnado.

De cualquier modo, este primer contacto con las TIC que tiene lugar en la escuela, permite que los jóvenes interesados busquen alternativas para su uso. La ventaja de las TIC es que atraen a la 
población joven por su componente lúdico. Por ese motivo su uso se extiende en contextos desfavorecidos, en los cuales a menudo, no existe conciencia de la necesidad más instrumental de acceder y saber utilizar estas herramientas. De acuerdo con los educadores entrevistados, en el caso de los chicos y chicas que acuden al TEB, el hecho de no disponer de acceso a las TIC en casa, no tiene porqué determinar el tipo de uso que realizan, ni el nivel de dominio que consiguen. Según ellos, esto depende sobre todo del interés personal. El acceso en casa permite una familiarización más rápida con las herramientas, pero a partir del momento en que se tienen los conocimientos básicos, todo lo que se pueda aprender para conseguir niveles de dominio más complejos, tiene que ver con esencialmente la motivación de cada uno y lógicamente, de las posibilidades ulteriores de acceso y aprendizaje.

Por otra parte, en el TEB hemos podido comprobar, como la fractura digital responde, no únicamente a razones socioeconómicas, sino también de género. El número de chicas que van al TEB se reduce a pocas excepciones. Según los educadores se trata de un círculo vicioso ya que, al representar una proporción muy pequeña del total de participantes, no se sienten cómodas entre tantos chicos y dejan de ir. Eso hace que la proporción de chicas no aumente y la situación se repita. De acuerdo con esta teoría, la única forma posible de que haya más chicas en el TEB es que todo un grupo cree su propio espacio. A parte de esto, los educadores exponen que las chicas no sienten tanto interés por las TIC como los chicos, ya que sus inquietudes se conducen más hacia el contacto con sus iguales, la conversación y la expresión de sus sentimientos, la manifestación de sus gustos, etc.

En general, todos los jóvenes con los que hablamos en el TEB se mostraron muy satisfechos por el hecho de tener un espacio libre en el barrio, en el que acceder gratuitamente a los ordenadores y a Internet. No obstante, encontramos algunas referencias entre los chicos más mayores y veteranos del centro a los aspectos negativos de haber incorporado las TIC al TEB. Por ejemplo, un chico nos comentó que le gustaba más como era el centro antes de tener ordenadores, ya que ahora todo giraba demasiado alrededor de ellos. Hizo referencia a la disminución de las relaciones sociales entre los participantes, especialmente entre los más pequeños que, tienen más tendencia a ensimismarse delante de la pantalla del ordenador.

“Antes era más comunicativo, más abierto. La mayoría de jóvenes están muy concentrados”.

En efecto, encontrar el equilibrio entre aprovechar el potencial de las TIC para atraer a los más jóvenes y evitar que estas se conviertan en la razón de todo lo que significa el TEB, es complicado. El equipo de responsables tiene el reto de conseguir que nadie se sienta excluido por no utilizar tanto las TIC, y a la vez proponer una oferta educativa y lúdica que responda a los intereses de la mayoría, cosa que consigue con la incorporación de las TIC.

Una de las cuestiones emergentes a partir de las observaciones y entrevistas realizadas fue la elevada motivación por comunicarse virtualmente a través de programas como el Messenger. Como ya hemos dicho, esta motivación converge con la de muchos otros chicos y chicas de todo el mundo con circunstancias vitales muy distintas. Pensamos que no se debe contemplar como algo negativo sino que, por el contrario, debería aprovechar-se como estímulo para la realización de diferentes actividades. Por ejemplo, organizando intercambios comunicativos con personas de otros centros o países a través de Internet, o incluso participando en proyectos educativos telemáticos.

En relación con la limitación del tiempo de utilización de los juegos y del Messenger, entendemos el propósito con que se está aplicando la medida en el TEB, pero pensamos que existe gran cantidad de juegos con contenidos muy interesantes desde un punto de vista pedagógico. A través de este tipo de juegos, los jóvenes pueden desarrollar capacidades y construir conocimientos. Por ello, pensamos que se constituye una oportunidad educativa, siempre y cuando estemos hablando de juegos adecuados.

Por último, creemos que seria necesario algún tipo de acción concreta frente a la falta de asistencia de las chicas a este tipo de centros. Como hemos señalado antes, en el TEB existe una proporción muy baja de chicas que participen en el conjunto de actividades. En el espacio libre, esta ausencia es especialmente notoria. Pensamos que debería analizarse cual es la causa, por ejemplo, a través del análisis de actividades que incorporan las TIC y que sí consiguen atraer a las chicas, como es el caso 
de la grabación de programas de radio en el TEB[4].

En estudios realizados en países como el Reino Unido, se ha observado que los chicos se sienten más atraídos que las chicas por las TIC, así el género se convierte una vez más en un factor de exclusión, en este caso en relación al acceso a las TIC con todo lo que eso representa. Frente a esta situación, opinamos que deben buscar soluciones, ya que muchas chicas como algunas de las que viven en el Raval, pueden convertirse en objeto de una triple exclusión social: 1) por ser inmigrantes y vivir en el barrio en el que viven; 2) por ser mujeres; y 3) por no tener las competencias en utilización de las TIC. Pensamos que este tipo de centros debería proponerse la asistencia de las chicas, como uno de sus objetivos prioritarios y realizar una búsqueda activa de opciones para conseguirlo.

Nuestra principal conclusión en este estudio exploratorio es que, en casos de vulnerabilidad social, las TIC se pueden utilizar para reclamar a los jóvenes y a partir de aquí trabajar cualquier cosa, dándole el trasfondo necesario. A través de éstas se pueden desarrollar capacidades, habilidades, conocimientos y en definitiva, competencias sociales muy necesarias a la hora de buscar un trabajo. Los centros categorizables en el ámbito de educación en el tiempo libre como el TEB, constituyen una oportunidad para niños y jóvenes en situaciones de riesgo de exclusión social, o con bajo rendimiento en la escuela.

En este tipo de centros, en que no existe una presión manifiesta por cumplir unos objetivos de aprendizaje, ni la obligación de realizar unas tareas determinadas como ocurre en la escuela, en que se genera una relación de confianza con los dinamizadores y dinamizadoras, los jóvenes se sienten relajados, y motivados para aprender mientras se entretienen. El hecho de acudir a este tipo de centros, además de darles formación y favorecer el desarrollo de competencias sociales y valores, les puede ayudar a configurar su red social y de recursos. Así, el contacto con vecinos y personas que trabajan en el barrio, les puede facilitar el acceso a diferentes oportunidades de promoción, ya sean laborales, formativas o sociales. Además de tener acceso a la información, disponen de la ayuda y el estímulo de un equipo de dinamizadores, que realizan una labor de soporte en la realización de los deberes de la escuela, en la búsqueda y selección de información, etc. lo cual puede incrementar su motivación por aprender.

Pese a la existencia de otros lugares en el barrio (como locutorios o bibliotecas) dónde los jóvenes pueden conectarse a Internet o utilizar ordenadores, la labor de centros como el TEB no es comparable, por su planteamiento educativo. Entre otras cosas, componentes como el trabajo en equipo, la educación intercultural, el aprendizaje o la creación personal, por ejemplo en la edición de vídeos, o la grabación de maquetas, etc., hacen que el uso de las TIC consiga un valor añadido.

Consideramos pues que, efectivamente, nos encontramos ante una buena práctica, que puede constituir un modelo transferible a diferentes situaciones y contextos, con el fin de superar, o prevenir situaciones de exclusión social con colectivos jóvenes.

\section{Referencias}

AREA, M. (coord) (2001) Educar en la Sociedad de la Información. Col. Aprender a ser. Bilbao, Desclée de Brouwer

BA, H.; TALLY, W.; TSIKALAS, K. (2002) Investigating Children's emerging digital literacies. Journal of Technology, Learning and Assessment, 4 (1). [En línea:<http://www.jtla.org>] [Fecha de consulta: junio de 2004]

BECTA (2001) The digital divide: a discussion paper. Prepared for the DIES by the Evidence Team, BECTA [En línea: http://www.becta.org.uk/research/reports/docs/digitaldivide.pdf] [Fecha de consulta: enero de 2002]

BRADER, A.W. (2001).Young people's use of ITC's: a practitioners' perspective. Presentado en Ethics, ITC and Social Exclusion Conference, Bolton, 2001. 
CASTEL, R. (1992). La inserción y los nuevos retos de las intervenciones sociales, en F. Álvarez-Úria (comp.). Marginación e inserción. Los nuevos retos de las políticas sociales. Madrid, Endymión.

CASTELLS, M. (2001) La era de la información. Economía, sociedad y cultura. Vol II. Mèxic, Ed. Siglo XXI.

FEIXA, C. (2001) Generació @. La joventut al segle XXI, Barcelona, Secretaria General de Joventut.

HELLAWELL, S. (2001). Beyond Access, ICT and social inclusion. London, Fabian Society.

LORENTE, S. (2002) Juventud y teléfonos móviles. Revista de Estudios de Juventud, 57. [En línea: <http://www.mtas.es/injuve>] [Fecha de consulta: junio de 2004]

MINOURA, Y. (2001) Children and media. En N. Kobayashi (ed) The bright and dark sides of the information revolution. A cultural ecological perspective. Tokio, Hoso Bunka Foundation

RODRÍGUEZ, E. (coord) (2004) Jóvenes y videojuegos: espacio, significación y conflictos. Madrid, INJUVE y Fundación de Ayuda contra la Drogadicción (FAD) [En línea: <http://www.mtas.es/injuve>] [Fecha de consulta: junio de 2004]

SUORONTA, J. (2004) Youth \& information and communication technologies. A World Youth Report, 2003. The global situation of young people. Naciones Unidas. [En línea: <http://www.un.org/esa/socdev/unyin/wyr/>] [Fecha de consulta: junio de 2004]

TAPSCOTT, D. (1998) Growing up digital: the rise of the net generation. New York, McGraw Hill

\section{Notas:}

[1] Este concepto se desarrolla con más amplitud en el artículo "Políticas para la inclusión social mediante Tecnologías de la información y la comunicación", de Iolanda García, de este mismo número.

[2] Para conocer más iniciativas de este tipo ver artículo "Políticas para la inclusión social mediante Tecnologías de la información y la comunicación” Iolanda García, en este mismo monográfico.

[3] La Fundació Catalana per la Recerca coordina un programa de sensibilización sobre la seguridad en

Internet, llamado "Internet Segura" (http://www.internetsegura.net/), cuyo objetivo es preservar los derechos de la infancia en relación con el uso de las redes electrónicas y especialmente Internet.

[4] Este tipo de actividad en el que las chicas trabajan juntas, que pueden controlar sin que se impliquen chicos, y a través del cual pueden tratar temas que les interesan y afectan directamente, tiene unas características que, por algún motivo, resultan atractivas para ellas, por lo que pensamos que podría servir como modelo. 